\title{
ROLE OF SOIL BEHAVIOR ON THE INITIAL KINEMATICS OF TSUNAMIGENIC SLIDES
}

\author{
A.S. BRADSHAW \\ Department of Civil Engineering, Merrimack College, North Andover, MA, USA \\ C. D.P. BAXTER, O-D. S. TAYLOR, and S. GRILLI \\ Departments of Ocean and Civil and Environmental Engineering, University of \\ Rhode Island, Narragansett, RI, USA
}

\begin{abstract}
Recent investigations on tsunami generation from submarine mass failures show that one of the most important factors influencing the source characteristics of the wave is the initial acceleration of the failure itself. In a number of these studies, a translational slide is modeled as a rigid body sliding down an inclined plane and basal resistance is neglected. In this paper, a similar rigid body model is proposed that incorporates basal resistance, which is related to the shear strength of the soil. Initial slide kinematics were investigated under two triggering mechanisms including overpressures at depth and rapid sedimentation. The model results show that soil behavior significantly influences the acceleration time history as well as the magnitude of the peak acceleration. The slide kinematics depend largely on the initial stress state and on the undrained residual shear strength of the soil along a potential failure surface, which highlights the importance of performing detailed geotechnical site investigations when assessing these geohazards. More research is needed to determine the influence of using more realistic basal friction models on the initial wave heights generated by submarine mass failures.
\end{abstract}

Keywords: Tsunamis, landslides, clay, overpressures, sedimentation

\section{Introduction}

Tsunamigenic mass failures are of major concern for proper risk analysis related to the development of offshore and coastal structures, seafloor resources and for the protection of coastal communities (Locat et al. 2001). There is a variety of types of submarine failures (Locat and Lee 2000); however many tsunamigenic slope failures can be classified into two basic categories (e.g. Grilli and Watts 2005): (1) slides, which are defined as thin translational failures with long runnout distances, and (2) slumps, which are thick rotational failures. The focus of this paper is on submarine slides in normally consolidated clay.

In order to investigate the generation of tsunamis from submarine mass failures and its sensitivity to governing parameters, Watts and Grilli (2003) and Grilli and Watts (2005) modeled a translational slide as a semi-elliptical or Gaussian shaped rigid body sliding down an inclined plane. A semi-elliptical body was shown to produce the largest (i.e. worst-case) initial tsunami. In their analyses, the basal resistance was assumed to be negligible as compared to hydrodynamic resistance, thereby limiting the number of parameters in the model. However, since the 
parameter of greatest influence on tsunami generation was shown to be the initial acceleration of the center of the failed mass (Haugen et al. 2005, Watts et al. 2005), removing the soil behavior may result in an acceleration time history that is not representative of actual slide motion.

This paper presents an analysis of the effect of basal friction on the initial acceleration of a submarine slide. A modified solid body model was developed, which includes the resistance to sliding due to the shear strength of the soil. First, a slide model developed by Grilli and Watts (2005) is described along with the governing equations of motion. The incorporation of a new basal resistance function into this model is described, and the impact of soil behavior on the slide kinematics is thus investigated.

\section{Slide Model}

The equation of center of mass motion for a 2-D semi-elliptical body moving down an inclined plane, as shown in Figure 1, is given by the following expression (Grilli and Watts 2005):

$$
\left(\gamma+C_{m}\right) \ddot{s}=(\gamma-1)\left(\sin \theta-C_{n} \cos \theta\right) g-C_{d} \frac{2}{\pi \cdot B} \dot{s}^{2}
$$

where $\gamma=$ ratio of the bulk density of the soil composing the slide to the density of water, $g=$ gravitational acceleration, $B=$ slide length, $C_{m}=$ added mass coefficient, $C_{n}=$ Coulomb friction coefficient, $C_{d}=$ hydrodynamic drag coefficient, $\ddot{s}=$ slide acceleration, and $\dot{s}=$ slide velocity (the upper dots denote time derivatives).

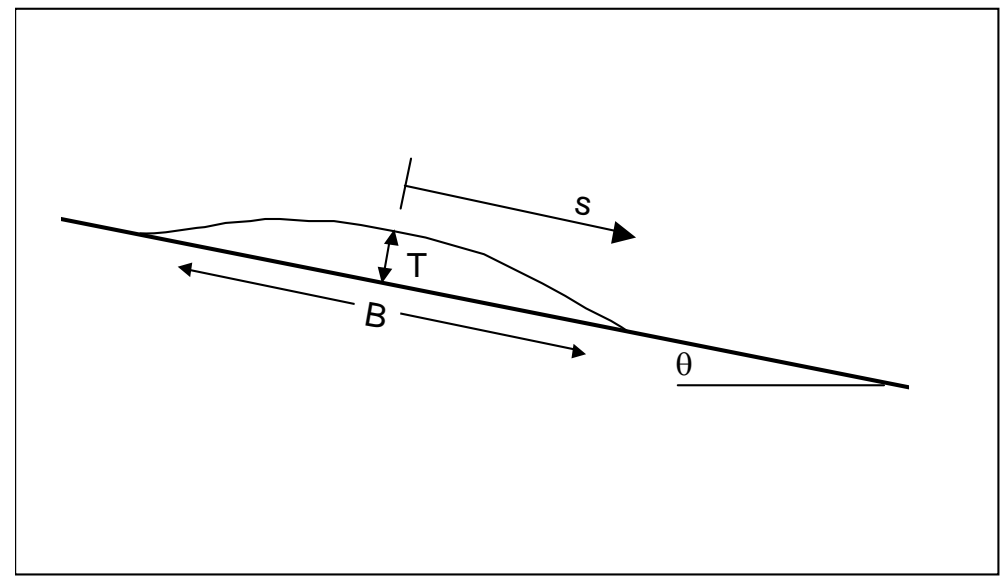

Figure 1. Rigid semi-elliptical body used in the underwater landslide model.

For translational slides, Grilli and Watts (2005) and Watts et al. (2005) assumed that $C_{n}$ was approximately zero thus eliminating the basal resistance term from Equation 1. To account for more realistic soil behavior, a revised equation of motion is proposed: 


$$
\left(\gamma+C_{m}\right) \ddot{s}=(\gamma-1) g \sin \theta-\frac{S(s, B)}{\rho_{w} \frac{\pi}{4} B T}-C_{d} \frac{2}{\pi \cdot B} \dot{s}^{2}
$$

where $S(s, B)=$ basal resistance function that depends on slide displacement $(s)$ and slide length $(B), \rho_{w}=$ density of water, and $T=$ slide thickness.

\section{Basal Resistance Function}

As a slide develops, the shear strength decreases from its peak value to a residual condition due to strain softening behavior. The onset of failure can occur if the shear strength is exceeded due to applied loads (e.g. rapid sedimentation), the shear strength is reduced (e.g. overpressures), or a combination of the two (e.g. earthquake loading). For this analysis, triggering due to both overpressures at depth and rapid sedimentation were considered. In order to develop a reasonable shear strength function, it is important to first understand the stress paths that occur before, during, and after landslide triggering. Figure 2 illustrates the stress paths for both cases, where the shear stress on a potential failure surface is plotted versus the normal effective stress.

In the case of overpressures at depth (Figure 2a), an increase in pore pressure causes a decrease in effective stress with no change in the driving shear stress. From an initial stress state, the stress path moves horizontally to the left in the diagram, during which time the soil swells slightly from the decrease in effective stress. Some deformation occurs at this point but triggering is not yet initiated. Eventually, the stress path reaches the failure envelope (defined as $\sigma^{\prime} \tan \phi_{p}{ }^{\prime}$ ) where the applied shear stress $\left(\tau_{\mathrm{f}}\right)$ is equal to the shear strength of the soil. Any further reduction in effective stress initiates landslide motion, and the soil is sheared under undrained conditions. With continued shear displacement, the strength eventually reaches the residual undrained shear strength $\left(S_{u r}\right)$ which is located on the residual strength envelope (defined by $\sigma^{\prime} \tan \phi_{r}{ }^{\prime}$ ). Since $\mathrm{S}_{\mathrm{ur}}$ is a steady-state strength, it remains constant at very large strains. It is important to note that landslide motion will only occur if the soil is strain softening (i.e. $\mathrm{S}_{\mathrm{ur}}<$ $\left.\tau_{\mathrm{f}}\right)$.

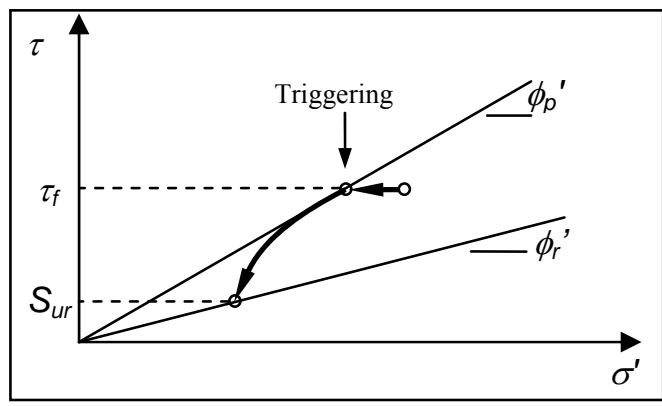

(a)

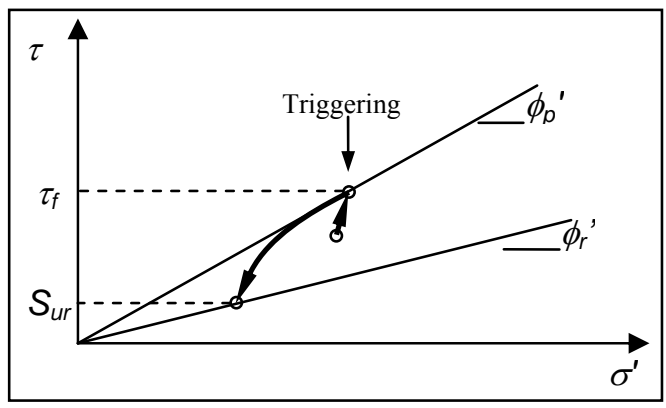

(b)

Figure 2. Stress paths showing the initiation of failure and reduction of shear strength during landslide triggering due to (a) overpressures at depth and (b) rapid sedimentation.

In the case of rapid sedimentation (Figure 2b), the thickness of the overburden soil increases thereby increasing the driving shear stresses within the slope. In low 
permeability soil layers (i.e. clays) the sedimentation may be so rapid that the soils do not have sufficient time to fully consolidate. Therefore, the effective stress will only increase slightly as the shear stress increases, causing the stress path to move up and to the right towards the failure envelope in the diagram. Similar to the first case, once the shear stress exceeds the strength of the soil, the motion of the slide is initiated and the clay is sheared undrained to a residual condition.

For purposes of modeling initial slide kinematics, only the conditions after triggering were considered. For the semi-elliptical body shown in Figure 1, the strength at failure is equal to the average driving shear stress, given by the following expression

$\tau_{f}=\rho_{w} \frac{\pi}{4} T \cdot(\gamma-1) g \sin \theta$

where $\theta=$ slope angle. Results of undrained ring shear tests performed on undisturbed samples of normally consolidated Drammen clay (Stark and Contreras 1996), shown in Figure 3, indicate that the undrained strength decreases logarithmically with shear displacement from peak to residual where it remains constant.

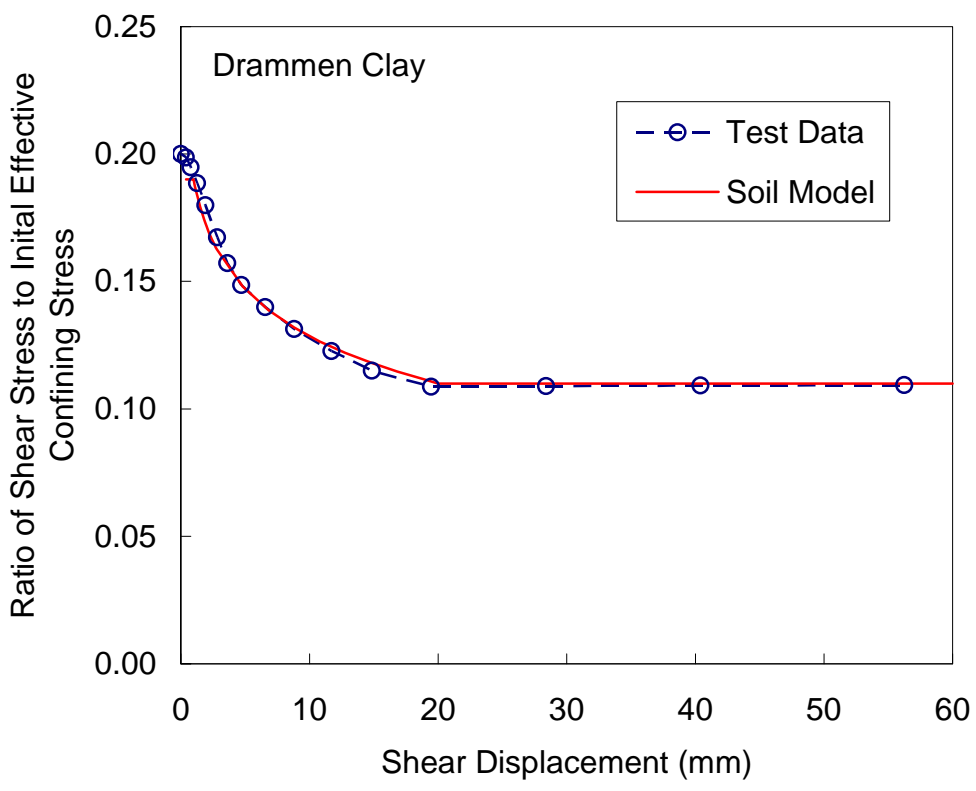

Figure 3. Ring shear test results obtained from an undisturbed sample of normally consolidated Drammen clay (after Stark and Contreras 1996). The soil model used in the slide modeling is also shown.

Large runout distances observed during past landslides also suggest that underwater landslides eventually reach a hydroplaning condition (e.g. Issler et al. 2003). Therefore, it was assumed that the basal resistance goes to zero for any portion of the slide that overrides the soils down slope of the initial slide location. Based on the results in Figure 3, the shear strength function was defined by the following set of equations

$S(s, B)=0.95 \tau_{f} \cdot(B-s) ; \quad s<0.001 \mathrm{~m}$ 


$$
\begin{aligned}
& S(s, B)=\left[S_{u r}+\frac{\left(0.95 \tau_{f}-S_{u r}\right)}{\log \left(\frac{s_{r}}{0.001}\right)} \cdot \log \left(\frac{s_{r}}{s}\right)\right] \cdot(B-s) ; 0.001 \mathrm{~m} \leq s \leq s_{r} \\
& S(s, B)=S_{u r} \cdot(B-s) ; \quad s>s_{r}
\end{aligned}
$$

where $S_{u r}=$ undrained residual shear strength $\left(P_{a}\right)$, and $s_{r}=$ displacement at which $S_{u r}$ is fully mobilized (m). The soil model is shown along with the laboratory test data in Figure 3.

\section{Initial Slide Kinematics}

The equation of motion (Equation 2) was solved numerically using a finite difference approach with the following slide parameters: $T=60 \mathrm{~m}, B=4 \mathrm{~km}, \theta=$ $10^{\circ}$, and $\gamma=1.8$. These parameters were chosen to illustrate the impact of basal resistance, and represent a relatively short slide on a steep slope (Canals et al. 2004). The coefficients $C_{m}$ and $C_{d}$ were taken to be unity (Grilli and Watts 2005). The numerical results were first validated by comparing them to the analytical solutions of Grilli and Watts (2005) for a translational slide having zero basal resistance. Subsequent model runs were then performed for the two cases described above assuming a residual strength ratio of 0.11 which is fully mobilized at $20 \mathrm{~mm}$ (Figure 3).

Figure 4 plots the time history of slide velocity and acceleration for the case of overpressures at depth. Two plots are shown; one assuming zero basal resistance (i.e. $S(s, B)=0$ ) and the other assuming $S(s, B)$ calculated using Equations 4 through 6 . When basal resistance is neglected, the maximum acceleration $(\sim 0.48$ $\mathrm{m} / \mathrm{s}^{2}$ ) occurs at $\mathrm{t}=0$ and gradually decreases to zero as the slide reaches a terminal velocity of $90 \mathrm{~m} / \mathrm{s}$. When soil shear strength is included, the slide eventually reaches the same terminal velocity only the acceleration time history is very different. The acceleration increases from zero at $\mathrm{t}=0$ to a maximum value of $\sim 0.38 \mathrm{~m} / \mathrm{s}^{2}$ at about $\mathrm{t}=270 \mathrm{~s}$ and then decreases back to zero. Soil behavior in this case had the effect of shifting the peak acceleration later in the time history and decreasing magnitude by about $20 \%$.

The velocity and acceleration time histories for the case of rapid sedimentation are shown in Figure 5. The various curves in the figure are shown to illustrate how the initial stress state of the clay can affect the acceleration time history. The $U$ in the legend indicates the average degree of consolidation on the potential failure surface just before triggering occurs. The curve at $U=100 \%$ is identical to the curve in Figure 4 because the clay was assumed to be fully consolidated in both cases. For reference, the curve for zero basal resistance is also shown in Figure 5. As shown in the figure, as $\mathrm{U}$ decreases the $S_{u r}$ decreases, and the time history shifts from the $U=100 \%$ curve toward the curve with no basal resistance. Similar to the previous case, when shear strength is included, the peak acceleration is less and typically occurs later in the time history. 

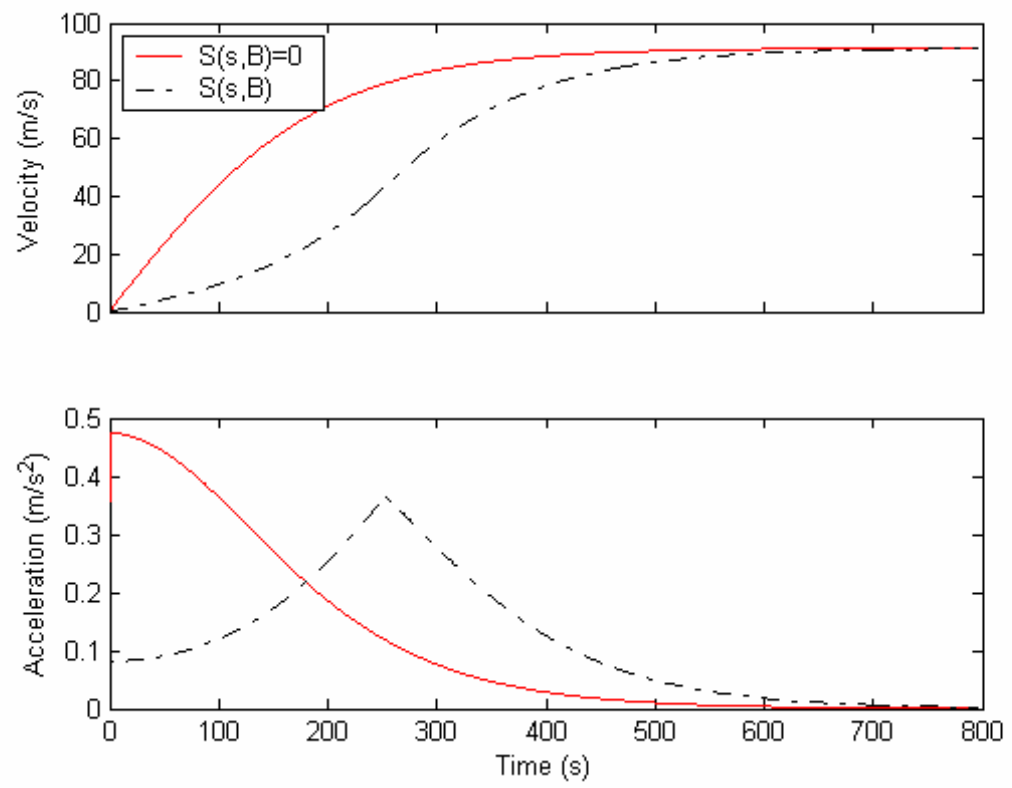

Figure 4. Time history of slide velocity and acceleration for the case of overpressures at depth $\left(\mathrm{B}=4 \mathrm{~km}, \mathrm{~T}=60 \mathrm{~m}\right.$, and $\left.\theta=10^{\circ}\right)$.
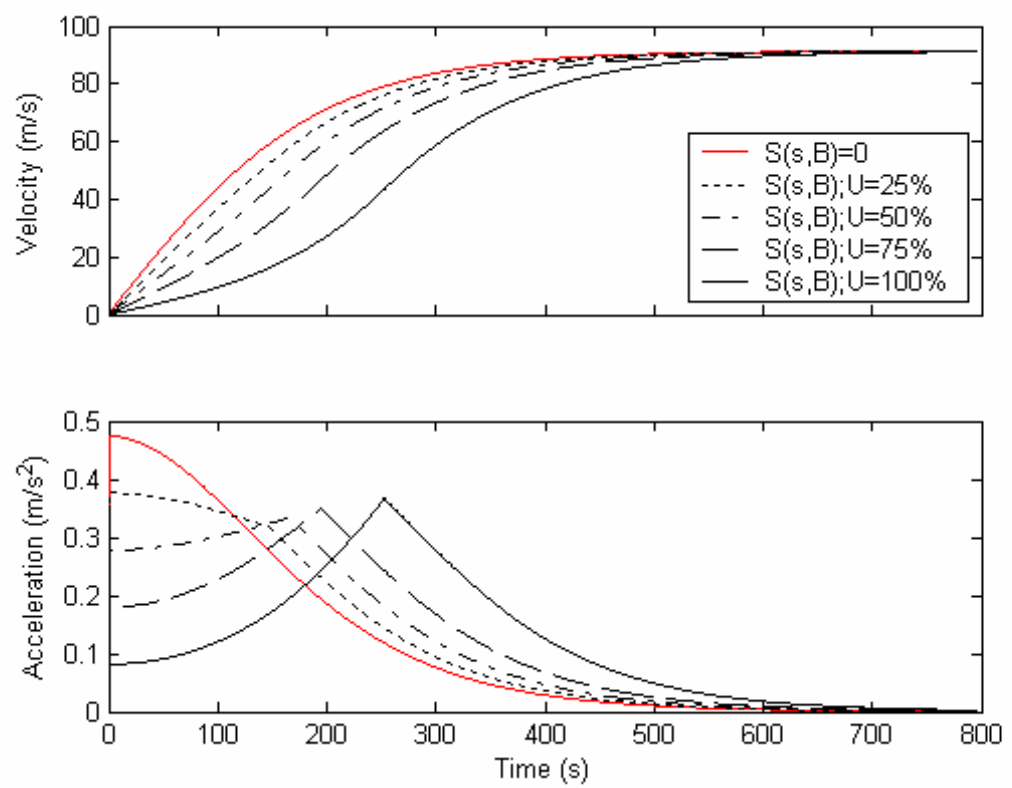

Figure 5 . Time history of slide velocity and acceleration for the case of rapid sedimentation $(B=4$ $\mathrm{km}, \mathrm{T}=60 \mathrm{~m}$, and $\theta=10^{\circ}$ ). The $\mathrm{U}$ in the legend indicates the average degree of consolidation along the failure surface when triggering occurs.

\section{Conclusions}

A modified solid body slide model was proposed that includes basal resistance that is a function of the undrained residual strength of the soil. The equation of motion was solved to obtain the time history of velocity and acceleration for a relatively short translational slide on a steep slope. The model results indicate that the soil shear strength had a significant influence on the acceleration time history of the slide. The effect of the modeled time histories on tsunami generation was not investigated in this paper. However, the model results do suggest the importance of characterizing both the initial stress state of the soils as well as their 
shear strength properties. Furthermore, identifying these properties in situ will ultimately allow for better prediction of actual landslide kinematics.

\section{Acknowledgements}

The authors would like to thank Dr. Jacques Locat for his thoughtful review comments during the final preparation of this manuscript.

\section{References}

Canals, M., Lastras, G., Urgeles, R., Casamor, J.L., Mienert, J., Cattaneo, A., De Batist, M., Haflidason, H., Imbo, Y., Laberg, J.S., Locat, J., Long, D., Longva, O., Masson, D.G., Sultan, N., and Bryn, P., 2004. Slope failure dynamics and impacts from seafloor and shallow sub-seafloor geophysical data: case studies from the COSTA project. Marine Geology, 213, p. 9-72.

Grilli, S.T., and Watts, P., 2005. Tsunami Generation by Submarine Mass Failure. I: Modeling, Experimental Validation, and Sensitivity Analyses. Journal of Waterways, Ports, Coastal, and Ocean Engineering. 131:6, p. 283-297.

Haugen, K.B., Løvholt, F., and Harbitz, C.B., 2005. Fundamental mechanisms for tsunami generation by submarine mass flows in idealized geometries. Marine and Petroleum Geology, 22, p. 209-217.

Issler, D., DeBlasio, F., Elverhoi, A., Ilstad, T., Haflidason, H., Bryn, P., and Lien, R., 2003. Issues in the assessment of gravity mass flow hazard in the Storegga area off the western Norwegian coast. In: Submarine Mass Movements and their Consequences. Locat, J., Meinert, J. (Eds.), Kluwer Academic Press, Netherlands, p. 231-238.

Locat, J., 2001. Instabilities along ocean margins: a geomorphological and geotechnical perspective. Marine and Petroleum Geology, 18, p. 503-512.

Locat, J., and Lee, H., 2002. Submarine landslides: advances and challenges. Canadian Geotechnical Journal, 39, p. 193-212.

Stark, T.D., and Contreras, I.A., 1996. Constant volume ring shear apparatus. Geotechnical Testing Journal, 19:1, p. 3-11.

Watts, P., and Grilli, S. T., 2003. Underwater landslide shape, motion, deformation, and tsunami generation. Proc., 13th Offshore and Polar Engineering Conf., International Society of Offshare and Polar Engineers, Cupertino, Calif., v.3, p. 364-371.

Watts, P., Grilli, S.T., Tappin, D.R., and Fryer, G.J., 2005. Tsunami Generation by Submarine Mass Failure. II: Predictive Equations and Case Studies. Journal of Waterways, Ports, Coastal, and Ocean Engineering. 131:6, p. 298-310. 